\title{
Hepatic Sclerosed Hemangioma: a case report and review of the literature
}

\author{
Shunsuke Miyamoto ${ }^{1}$, Akihiko Oshita $^{1,2^{*}}$, Yutaka Daimaru ${ }^{3}$, Masaru Sasaki ${ }^{1}$, Hideki Ohdan² and Atsushi Nakamitsu ${ }^{1}$
}

\begin{abstract}
Background: Although cavernous hemangioma is one of the most frequently encountered benign hepatic neoplasms, hepatic sclerosed hemangioma is very rare. We report a case of hepatic sclerosed hemangioma that was difficult to distinguish from an intrahepatic cholangiocarcinoma by imaging studies.

Case presentation: A 76-year-old male patient with right hypochondralgia was referred to our hospital. Abdominal ultrasonography revealed a heterogeneously hyperechoic tumor that was $59 \mathrm{~mm}$ in diameter in segment 7 of the liver. Dynamic computed tomography showed a low-density tumor with delayed ring enhancement. Gadolinium-ethoxybenzyl-diethylenetriamine pentaacetic acid-enhanced magnetic resonance imaging (EOB-MRI) demonstrated a low-signal intensity mass with ring enhancement on T1-weighted images. The mass had several high-signal intensity lesions on T2-weighted images. EOB-MRI revealed a hypointense nodule on the hepatobiliary phase. From these imaging studies, the tumor was diagnosed as intrahepatic cholangiocarcinoma, and we performed laparoscopy-assisted posterior sectionectomy of the liver with lymph node dissection in the hepatoduodenal ligament. Histopathological examination revealed a hepatic sclerosed hemangioma with hyalinized tissue and collagen fibers.
\end{abstract}

Conclusion: Hepatic sclerosed hemangioma is difficult to diagnose preoperatively because of its various imaging findings. We report a case of hepatic sclerosed hemangioma and review the literatures, especially those concerning imaging findings.

Keywords: Hepatic, Sclerosed, Hemangioma, US, CT, MRI, FDG-PET

\section{Background}

The preoperative diagnosis of hepatic sclerosed hemangioma is very difficult, even with recent developments in radiological modalities, because it is an extremely rare benign disorder and its radiological features resemble those of hepatic malignancies such as cholangiocarcinoma and metastatic liver cancer [1,2]. We report a case of a hepatic sclerosed hemangioma, that had been preoperatively misdiagnosed as an intrahepatic cholangiocarcinoma and been resected, and review the relevant literature, especially summarizing the imaging findings of hepatic sclerosed hemaigioma.

\footnotetext{
* Correspondence: oshita-akihiko@umin.ac.jp

'Department of Surgery, JA Hiroshima General Hospital, 1-3-3, Jigozen, 738-8503, Hatsukaichi, Japan

${ }^{2}$ Department of Gastroenterological and Transplant Surgery, Applied Life Sciences, Institute of Biomedical and Health Sciences, Hiroshima University, Hiroshima, Japan

Full list of author information is available at the end of the article
}

\section{Case presentation}

A 76-year-old male patient had consulted a doctor for upper abdominal pain 16 months before being referred to us and had been followed up. Because plain computed tomography $(\mathrm{CT})$ revealed a space-occupying lesion in the liver, he was referred to our hospital. A laboratory workup on admission showed that total bilirubin, aspartate aminotransferase, alanine aminotransferase, alkaline phosphatase, gamma-glutamyl transpeptidase, albumin, and creatinine were all within normal ranges. Tumor markers including alpha-fetoprotein, protein induced by vitamin $\mathrm{K}$ absence or antagonist-II, carcinoembryonic antigen, and carbohydrate antigens 19-9 were also within the normal limits (Table 1).

Abdominal ultrasonography (US) revealed a well-defined, heterogeneously hyperechoic mass that was $59 \mathrm{~mm}$ in diameter in segment 7 of the liver (Figure 1). Plain CT revealed a low-density $60-\mathrm{mm}$ sized mass with an irregular margin. Dynamic CT revealed early ring enhancement in the peripheral part on the arterial phase and 
Table 1 Review of imaging features for Hepatic Sclerosed Hamangioma

\begin{tabular}{|c|c|c|c|c|c|c|c|c|c|c|c|c|c|}
\hline Case & Year & Author & Age & Gender & Location & Size (mm) & US & Plain CT & Dynamic CT & MRI (T1/T2) & РET-CT & Preoperative diagnosis & Final diagnosis \\
\hline 1 & 1995 & Ishii & 81 & $\mathrm{~F}$ & S3 & 25 & Low & Low & Ring enhanced & Low/Low & - & Not determined & sclerosed hemangioma \\
\hline 2 & 1995 & Haratake & 64 & $\mathrm{~F}$ & S8 & 26 & - & Low & Ring enhanced & - & - & Metastatic liver cancer & sclerosed hemangioma \\
\hline 3 & 1996 & Kobayashi & 49 & $\mathrm{~F}$ & S7 & 22 & High & Low & Ring enhanced & Low/High & - & Not determined & sclerosed hemangioma \\
\hline 4 & 1998 & Ukai & 66 & $\mathrm{~F}$ & S6 & 10 & Low & Low & Ring enhanced & Low/High & - & Hepatocellular carcinoma & sclerosed hemangioma \\
\hline 5 & 2000 & Yamashita & 67 & $\mathrm{~F}$ & S4 & 50 & Low & Low & Ring enhanced & High/High & - & Metastatic liver cancer & sclerosing hemangioma \\
\hline 6 & 2001 & Okada & 77 & M & S8 & 23 & High & Low & Not enhanced & - & - & Metastatic liver cancer & sclerosed hemangioma \\
\hline 7 & 2001 & Aibe & 67 & $\mathrm{~F}$ & S4 & 40 & - & Low & Not enhanced & High/High & - & Metastatic liver cancer & sclerosed hemangioma \\
\hline 8 & 2003 & Hayakawa & 70 & $\mathrm{~F}$ & S2 & 30 & Low & Low & Ring enhanced & Low/Iso-High & - & Not determined & sclerosed hemangioma \\
\hline 9 & 2005 & Morikawa & 66 & M & S8 & 50 & Iso & Low & Ring enhanced & Low/High & Not accumulated & Not determined & sclerosed hemangioma \\
\hline 10 & 2005 & Lee & 65 & $\mathrm{~F}$ & S6 & 53 & - & - & Ring enhanced & Low/High & - & Hepatocellular carcinoma & sclerosing hemangioma \\
\hline 11 & 2005 & Okamoto & 50 & $\mathrm{~F}$ & S3 & 30 & Low & Low & Ring enhanced & - & - & sclerosed hemangioma & sclerosed hemangioma \\
\hline 12 & 2006 & Hamatsu & 59 & M & S8 & 25 & High & Low & Ring enhanced & - & - & Metastatic liver cancer & sclerosed hemangioma \\
\hline 13 & 2006 & Hayashi & 82 & $\mathrm{~F}$ & $S 2 / 3$ & 55 & High & Low & Not enhanced & Low/High & - & Gastric submucosal tumor & sclerosed hemangioma \\
\hline 14 & 2006 & lida & 77 & $\mathrm{~F}$ & S2 & 39 & High & Low & Ring enhanced & Low/Low-High & Not accumulated & Not determined & sclerosing hemaigioma \\
\hline 15 & 2007 & Sawai & 67 & $\mathrm{~F}$ & Right robe & 145 & Low & Low & Ring enhanced & Low/High & - & Not determined & sclerosed hemangioma \\
\hline 16 & 2008 & Kaji & 65 & $\mathrm{~F}$ & S5 & 25 & Low & Low & Ring enhanced & Low/lso-High & - & Cholangiocarcinoma & sclerosed hemangioma \\
\hline 17 & 2008 & Tsumaki & 70 & $\mathrm{~F}$ & S8 & 47 & Low & Low & Ring enhanced & Low/High & - & Liver sclerosed hemangioma & sclerosed hemangioma \\
\hline 18 & 2008 & Mori & 77 & $\mathrm{~F}$ & S6 & 100 & High & Low & Not enhanced & Low/High & - & Cholangiocarcinoma & sclerosed hemangioma \\
\hline 19 & 2010 & Yoshida & 75 & $\mathrm{~F}$ & S5/6 & 37 & High & Low & Ring enhanced & Low/High & Not accumulated & Cholangiocarcinoma & sclerosing hemaigioma \\
\hline 20 & 2010 & Usui & 57 & $\mathrm{~F}$ & S2 & 17 & Low & Low & Ring enhanced & Low/High & - & Metastatic liver cancer & sclerosed hemangioma \\
\hline 21 & 2010 & Jin & 52 & M & $\mathrm{S} 6 / 7$ & 38 & - & - & Ring enhanced & Low/High & - & Hepatocellular carcinoma & sclerosed hemangioma \\
\hline 22 & 2010 & Hida & 75 & $\mathrm{~F}$ & S5/6 & 30 & High & - & Ring enhanced & Low/High & - & Metastatic liver cancer & sclerosed hemangioma \\
\hline 23 & 2011 & Miyaki & $60^{\prime} \mathrm{s}$ & $\mathrm{F}$ & S3 & 30 & Low & Low & - & Low/High & - & Liver sclerosed hemangioma & sclerosed hemangioma \\
\hline 24 & 2011 & Kitami & 72 & $\mathrm{~F}$ & S3 & 55 & Low & Low & Ring enhanced & Low/High & - & Cholangiocarcinoma & sclerosed hemangioma \\
\hline 25 & 2011 & Tanaka & 71 & M & S6 & 15 & High & Low & Ring enhanced & - & - & Hepatocellular carcinoma & sclerosed hemangioma \\
\hline 26 & 2011 & Mikami & 74 & $\mathrm{~F}$ & S2 & 22 & Low & Low & Ring enhanced & Low/High & Not accumulated & Not determined & sclerosed hemangioma \\
\hline 27 & 2011 & Shin & 50 & M & Right robe & 100 & Iso-Low & Low & Ring enhanced & Low/High & Not accumulated & Liver sclerosing hemangioma & sclerosing hemangioma \\
\hline 28 & 2012 & Wakasugi & 61 & $\mathrm{~F}$ & S2, S5 & 25,5 & Low & - & Ring enhanced & Low/High & - & Metastatic liver cancer & sclerosed hemangioma \\
\hline 29 & 2012 & Yamada & 75 & M & \$8 & 11 & - & Low & Ring enhanced & Low/High & Not accumulated & Metastatic liver cancer & sclerosed hemangioma \\
\hline 30 & 2013 & Song & 63 & $\mathrm{~F}$ & $\mathrm{~S} 2 / 3$ & 91 & - & Low & Ring enhanced & - & - & Not determined & sclerosing hemangioma \\
\hline 31 & 2013 & Shimada & 63 & M & S8 & 10 & - & Low & Ring enhanced & Low/High & - & Atypical hemangioma & sclerosed hemangioma \\
\hline 32 & 2015 & OUR CASE & 76 & M & $56 / 7$ & 59 & High & Low & Ring enhanced & Low/High & - & Cholangiocarcinoma & sclerosed hemangioma \\
\hline
\end{tabular}




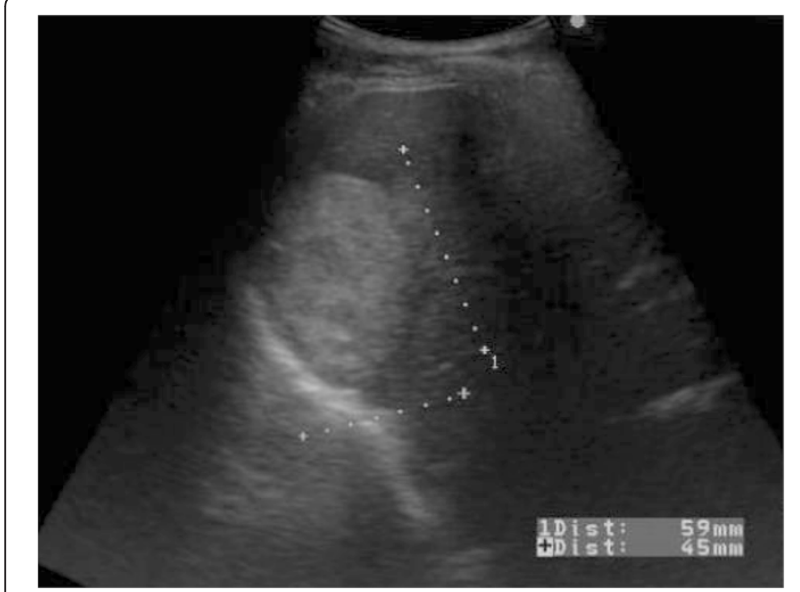

Figure 1 Abdominal ultrasonography (US). US showed a heterogeneously hyperechoic mass in segment 7 of the liver.

internal heterogeneous enhancement on the delayed phase (Figure 2). Gadolinium-ethoxybenzyl-diethylenetriamine pentaacetic acid-enhanced magnetic resonance imaging (EOB-MRI) showed that the tumor had low-signal intensity on T1-weighted images and that the mass had some high-signal intensity foci in the tumor on T2-weighted images. EOB-MRI showed no uptake in the corresponding area on the hepatobiliary phase and ring enhancement in the peripheral part on the arterial phase and the portal phase (Figure 3).

Laparoscopy-assisted posterior sectionectomy and cholecystectomy including lymph node dissection in the hepatoduodenal ligament were performed for a preoperative diagnosis of intrahepatic cholangiocarcinoma. The resected specimen revealed a white solid mass, sized $61 \times 46 \mathrm{~mm}$. The cut surface of the tumor was elastic, soft, and homogeneous with the smooth margin including some faint red spots up to $10 \mathrm{~mm}$ in size (Figure 4a).

Histopathological examination showed that the tumor was composed of fibrous connective tissue highlighted with collagen fibers and various sizes of cavernous hemangioma tissue with some hyaline degeneration secondary to thrombus, necrosis, or cicatrization, resulting in a hepatic sclerosed hemangioma (Figure 4b).

The postoperative course was uneventful. The patient was discharged on postoperative day 6 .

\section{Discussion}

Hepatic sclerosed hemangioma, first reported by Ishii in 1995 [1], is a rare disease, detected and reported in only 2 out of 1000 cases on autopsy [3]. We found only 9 cases in PubMed by manual searching for the terms "hepatic, sclerosed, hemangioma" and "hepatic, sclerosing, hemangioma" from January 1983 to January 2015. Additionally, we found 22 cases in ICHUSHI, a bibliographic database established in 1903 and being updated by the Japan Medical Abstracts Society, contains bibliographic citations and abstracts from more than 2500 biomedical journals and other serial publications published in Japanese. The 32 cases, including our case, are summarized in Table 1 [1,4-33].

Hepatic sclerosed hemangioma is caused by degenerative changes such as thrombus formation, necrosis, and scar formation of liver cavernous hemangioma, but the mechanism for degenerative changes in the hepatic cavernous hemangioma has not been well clarified at present [34].

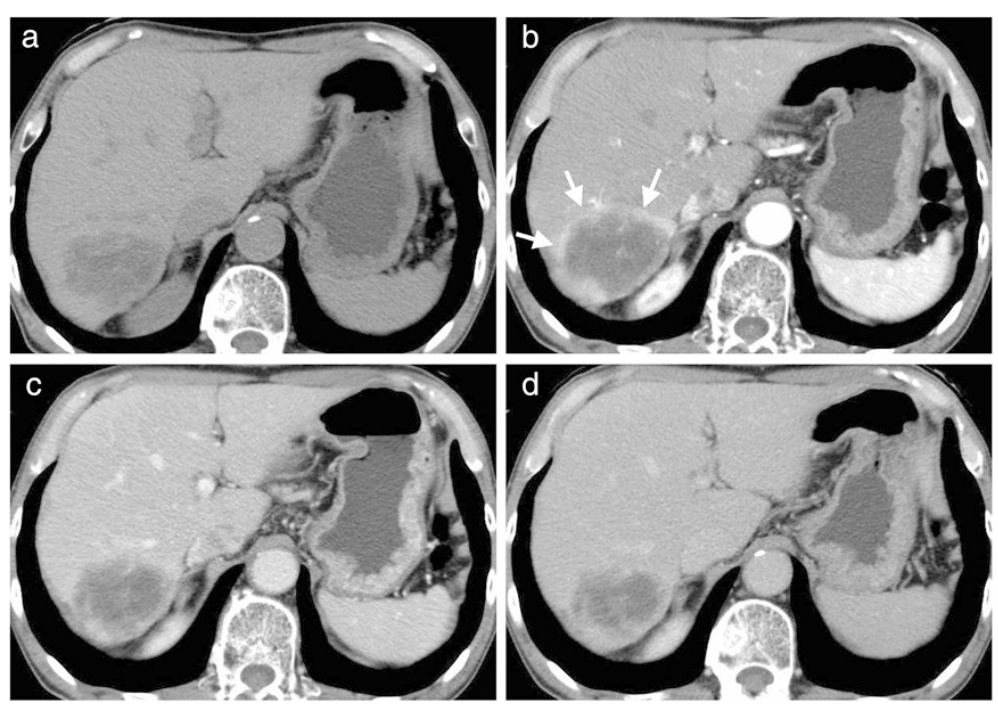

Figure 2 Abdominal computed tomography (CT). (a) plain, (b) arterial phase, (c) portal venous phase, and (d) delayed phase. Plain CT showed a low-density mass. Dynamic CT showed the ring enhancement in the peripheral part on the arterial phase (arrow). 


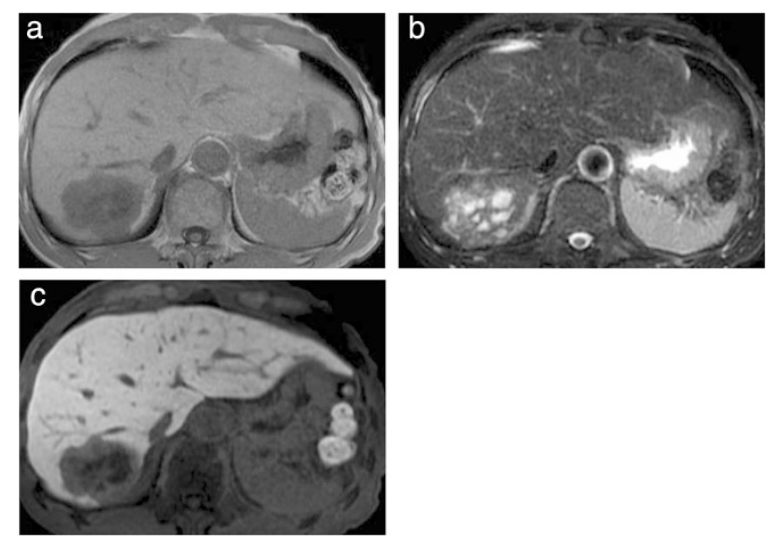

Figure 3 Magnetic resonance imaging (MRI). (a) T1-weighted image, (b) T2-weighted image, and (c) ethoxybenzyl (EOB)-MRI on the hepatobiliary phase. The tumor had low-signal intensity on T1-weighted and some high-signal intensity nodules in the tumor on T2-weighted images. EOB-MRI showed no uptake in the corresponding area on the hepatobiliary phase.

Concerning the imaging studies, Doyle et al. summarized the imaging findings of 10 hepatic sclerosed hemangioma lesions and found the characteristic features to include a geographic pattern, capsular retraction, decrease in size over time, loss of previously seen regions of enhancement [2]. And additional characteristic, features included the presence of transient hepatic attenuation difference, ring enhancement, and nodular regions of intense enhancement as seen in typical hemangioma. In our series reviewed the average size of the hepatic sclerosed hemangiomas was $42.3 \mathrm{~mm}$, ranging from 10 to $145 \mathrm{~mm}$. Abdominal US showed a hyperechoic mass in 11 cases and a hypoechoic tumor in 13 cases. Plain CT was likely to show a low-density mass, and dynamic
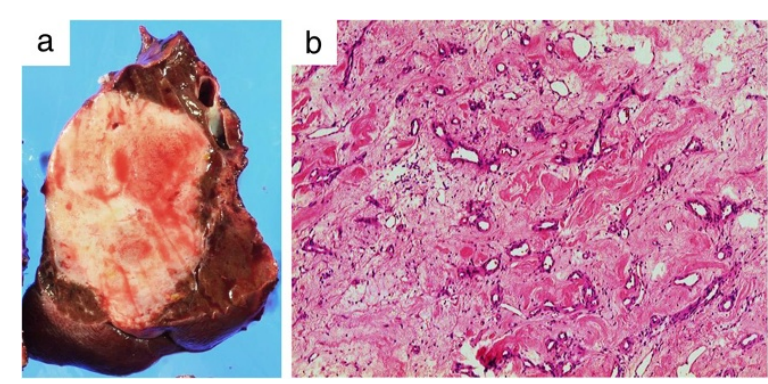

Figure 4 Resected specimen. (a) Surface of slice. The cut surface of the tumor reveals a white solid mass $(61 \times 46 \mathrm{~mm}$ in size) that was elastic, soft, and homogeneous with a smooth margin including some faint red spots, sized $1 \mathrm{~cm}$. (b) Hematoxylin and eosin staining (magnification, $\times 100$ ). The tumor was composed of fibrous connective tissue highlighted with collagen fiber and various sizes of cavernous hemangioma tissue with some hyaline degeneration secondary to thrombus, necrosis, or cicatrization.
CT showed ring enhancement, resembling metastatic liver cancer or intrahepatic cholangiocarcinoma, in 27 of 31 reported cases. MRI showed a low-intensity signal in 24 of 26 reported cases on T1-weighted images and a highintensity signal in 22 of 26 reported cases on T2weighted images. The radiological features revealed by dynamic CT and MRI resembled those of hepatic malignancies, leading to preoperative misdiagnosis. Whereas, $\left[{ }^{18} \mathrm{~F}\right]$-fluorodeoxyglucose positron emission tomography (FDG-PET), performed in just 6 cases, showed no accumulation of $\left[{ }^{18} \mathrm{~F}\right]-\mathrm{FDG}$ (Table 1). FDG-PET could be helpful in preoperative diagnosis to distinguish benign sclerosed hemangioma from malignant tumors such as intrahepatic cholangiocarcinomas or metastatic liver cancers. We may have had to perform FDG-PET preoperatively.

Surgical resection for hepatic sclerosed hemangioma is controversial. Most of the tumors reported were resected due to a preoperative misdiagnosis of malignancy (Table 1). To make a definite diagnosis of such hepatic tumors, percutaneous needle biopsy is not acceptable because of the possibility of dissemination of the cancer cells if the tumor is malignant. Therefore we would suggest that hepatic resections are chosen for the management of hepatic sclerosed hemangioma at present.

Makhlouf and Ishak compared the findings of sclerosed hemangioma and sclerosing cavernous hemangioma. According to their theory, recent hemorrhages and hemosiderin deposits rich in mast cells are present in the sclerosing hemangioma. While, fibrosis, increased elastic fibers, and dystrophic or psammomatous calcifications with a decreased number of mast cells can be observed in the sclerosed hemangioma [35]. Our case showed a fibrous connective tissue highlighted with collagen fibers and various sizes of cavernous hemangioma tissue with some hyaline degeneration. These findings are consistent with features of hepatic sclerosed hemangioma, resulting in the final diagnosis.

\section{Conclusion}

We report a case with a hepatic sclerosed hemangioma. Although it is a rare disease, it is important to distinguish hepatic sclerosed hemangioma from hepatic malignancies. However, it is extremely difficult to diagnose precisely from imaging studies. If the possibility of a malignant tumor cannot be ruled out, hepatic resection might be selected for diagnostic therapy.

\section{Consent}

Written informed consent was obtained from the patient for publication of this case report and any accompanying images. A copy of the written consent is available for review by the Editor of this journal. 


\section{Abbreviations}

EOB-MRI: Gadolinium-ethoxybenzyl-diethylenetriamine pentaacetic acidenhanced magnetic resonance imaging; $C \mathrm{C}$ : Computed tomography; US: Ultrasonography; FDG-PET: $\left[{ }^{18} \mathrm{~F}\right]$-fluorodeoxyglucose positron emission tomography.

\section{Competing interests}

The authors declare that they have no competing interests.

\section{Authors' contributions}

The first two authors contributed equally to this work. SM drafted the paper and collected date and reviewed the text. AO performed the operation, helped SM to draft the paper and made the final revision. YD diagnosed this disease. MS and AN assisted the operation. $\mathrm{HO}$ made the expert assistance. All authors read and approved the final manuscript.

\section{Author details}

'Department of Surgery, JA Hiroshima General Hospital, 1-3-3, Jigozen, 738-8503, Hatsukaichi, Japan. ²Department of Gastroenterological and Transplant Surgery, Applied Life Sciences, Institute of Biomedical and Health Sciences, Hiroshima University, Hiroshima, Japan. ${ }^{3}$ Department of Pathology, JA Hiroshima General Hospital, Hatsukaichi, Japan.

Received: 21 May 2014 Accepted: 28 March 2015

\section{Published online: 17 April 2015}

\section{References}

1. Ishii T, Takahara O, Sano I, Taniguchi H, Nakao S, Eida K, et al. Sclerosing Hemangioma of the liver. Nagasaki Med J. 1995;70(1):23-6.

2. Doyle DJ, Khalili K, Guindi M, Atri M. Imaging features of sclerosed hemangioma. Am J Roentgenol. 2007;189(1):67-72.

3. Berry CL. Solitary "necrotic nodules" of the liver: a probable pathogenesis. J Chin Pathol. 1985;38(11):1278-90.

4. Haratake J, Arai K, Makino H. Hemangioma and hyalinized hemangioma Jpn J Clin Med. 1995;7:336-8

5. Kobayashi S, Demachi H, Akakura Y, Miyata S, Konishi K, Tsuji M, et al. A case of sclerosing cavernous hemangioma of the liver. Jpn J Clin Radiol. 1996:41:567-70.

6. Ukai K, Onidera H, Mikuni J, Ouchi K. A case of sclerosed hemangioma of the liver. Liver. 1998;39(9):638-42.

7. Yamashita $Y$, Shimada M, Taguchi $K$, Gion T, Hasegawa H, Utsunomiya T, et al. Hepatic sclerosing hemangioma mimicking a metastatic liver tumor: report of a case. Surg Today. 2000;30:849-52

8. Okada S, Tsuyama H, Kurita K, Onchi H, Inoue T, Kinoshita K, et al. A case of sclerosing hemangioma with cancer of the desending colon. J Jpn Surg Assoc. 2001;62(3):757-60

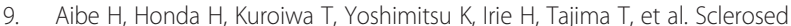
hemangioma of the liver. Abdom Imaging. 2001;26:496-9.

10. Hayakawa T, Itou M, Taniguchi S, Ideno M, Konno T, Hatayama J. A case of sclerosing hemangioma of the liver. J Med Assoc South Hokkaido. 2001:38:180-3.

11. Lee VT, Magnaye M, Tan HW, Thng CH, Ooi LL. Sclerosing haemangioma mimicking hepatocellular carcinoma. Singapore Med J. 2005;46(3):140-3.

12. Morikawa M, Ishida M, lida A, Katayama K, Yamaguchi A, Imamura Y. Sclerosed hemangioma of the liver mimicking metastatic liver cancer. J Jpn Surg Assoc. 2005;66(7):1698-702.

13. Okamoto E, Satou S, Takahashi Y, Ohshima N, Azumi T, Furuta K, et al. A case of hepatic sclerosed hemangioma in patient with fatty liver. J Shimane Med Assoc. 2005;25(3):60-4

14. Hamatsu T, Kuroda Y, Hunahashi S, Shima I, Iso Y. Sclerosed hemangioma of the liver mimicking metastatic liver tumor of colon cancer. J Jpn Surg Assoc. 2006;67(4):856-60

15. Hayashi K, Ohara H, Kitajima Y, Tanaka S, Takada H, Imai E, et al. A case of hepatic sclerosed hemangioma mimicking gastric submucosal tumor. Kanzo. 2006:47(10):474-81.

16. lida H, Tango Y, Tsutamoto Y, Harimura T, Tanaka K, Takao T, et al. A resected case of Sclerosed hemangioma. Jpn J Gastroenterol Surg. 2006;39(9): 1493-7

17. Sawai K, Ueda N, Senda K, Kimura T, Sawa T. A case of sclerosing hemangioma of the liver. J J.jn Surg Assoc. 2007;68(9):2293-8.
18. Kaji S, Koike N, Suzuki S, Harada N, Suzuki M, Hanyu F. A case of hepatic sclerosed hemangioma mimicking cholangiocell carcinoma. J Jpn Surg Assoc. 2008;69(5):1181-5

19. Tsumaki N, Waguri N, Yoneyama O, Hama I, Kawahisa J, Yokoo K, et al. A case of hepatic sclerosed hemangioma with a significant morphological change over a period of 17 years. Kanzo. 2008;49(6):268-74.

20. Mori H, Ikegami T, Imura S, Shimada M, Morine $Y$, Kanemura H, et al. Sclerosed hemangioma of the liver: report of a case and review of the literature. Hepatol Res. 2008;38:529-33.

21. Yoshida T, Sugimachi K, Gion T, Soejima Y, Aijima S, Takatomi S, et al. A case of sclerosing hemangioma mimicking a malignant liver tumor. J Clin Surg. 2010;65(3):451-5.

22. Usui T, Shiozawa S, Kim DH, Tsuchiya A, Kuhara K, Yokomizo H, et al. A case of sclerosed hemangioma mimicking a metastatic liver tumor. J Jpn Coll Surg. 2010;35(1):89-93.

23. Jin S-Y. Sclerosed hemangioma of the liver. Korean J Hepatol. 2010;16(4):410-3.

24. Hida T, Nishie A, Tajima T, Taketomi A, Aishima S, Honda H. Sclerosed hemangioma of the liver: possible diagnostic value of diffusion-weighted magnetic resonance imaging. Jpn J Radiol. 2010;28:235-8.

25. Miyaki D, Aikata H, Waki K, Murakami E, Hashimoto Y, Nagaoki Y, et al. Significant regression of a cavernous hepatic hemangioma to a sclerosed hemangioma over 12 years: a case study. Nihon Shokakibyo Gakkai Zasshi. 2011;108(6):954-61.

26. Kitami C, Kawachi Y, Nishimura A, Makino S, Kawahara M, Nikuni K Sclerosed hemangioma of the liver -report of a case-. J Jpn Surg Assoc. 2011;72(12):3120-4.

27. Tanaka T, Moriya T, Fukuda S, Yoshifuku Y, Fujino H, Miwata T, et al. A case of sclerosed hemangioma of the liver was difficult to differentiate hepatocellular carcinoma was found during examination of chronic hepatitis C. HBP Imaging. 2011;13(6):646-52.

28. Mikami J, Tominaga M, Sendo H, Maeda Y, Fujino Y, Koma Y, et al. A case of hepatic sclerosing hemangioma mimicking a malignant liver tumor. J Jpn Surg Assoc. 2011;72(4):965-71.

29. Shin YM. Sclerosing hemangioma in the liver. Korean J Hepatol. 2011;17(3):242-6.

30. Wakasugi M, Ueshima N, Akamatsu D, Tori M, Tsujimoto M, Nishida T. A case of multiple sclerosed hemangioma mimicking a metastatic liver tumor. J Clin Surg. 2012;67(12):1461-5.

31. Yamada S, Shimada M, Utsunomiya T, Morine $Y$, Imura S, Ikemoto T, et al. Hepatic sclerosed hemangioma which was misdiagnosed as metastasis of gastric cancer : report of a case. J Med Invest. 2012;59:270-4.

32. Song JS, Kim YN, Moon WS. A sclerosing hemangioma of the liver. Clin Mol Hepatol. 2013;19(4):426-30.

33. Shimada $Y$, Takahashi $Y$, Iguchi $H$, Yamazaki H, Tsunoda H, Watanabe M, et al. A hepatic sclerosed hemangioma with significant morphological change over a period of 10 years: a case report. J Med Case Rep. 2013;28(7):139.

34. Goodman ZD. Benign tumors of the liver. In: Okuda K, Ishak KG, editors. Neoplasm of the liver. Tokyo: Springer; 1987. p. 105-25.

35. Makhlouf HR, Ishak KG. Sclerosed hemangioma and sclerosing cavernous hemangioma of the liver: a comparative clinicopathologic and immunohistochemical study with emphasis on the role of mast cells in their histogenesis. Liver. 2002;22(1):70-8.

\section{Submit your next manuscript to BioMed Central and take full advantage of:}

- Convenient online submission

- Thorough peer review

- No space constraints or color figure charges

- Immediate publication on acceptance

- Inclusion in PubMed, CAS, Scopus and Google Scholar

- Research which is freely available for redistribution 